\title{
INFLUÊNCIA DO MÉTODO DE EXTRAÇÃO NOS TEORES DE METILXANTINAS EM ERVA-MATE (Ilex paraguariensis A. ST.-HIL., AQUIFOLIACEAE)
}

\author{
Simone C. B. Gnoatto e Valquiria L. Bassani \\ Faculdade de Farmácia, Universidade Federal do Rio Grande do Sul, Av. Ipiranga, 2752, 90610-000 Porto Alegre - RS, Brasil \\ Geraldo C. Coelho \\ Departamento de Biologia e Química, Universidade de Ijuí, CP 560, 98700-000, Ijuí - RS, Brasil \\ Eloir P. Schenkel* \\ Departamento de Ciências Farmacêuticas, Universidade Federal de Santa Catarina, CP 476, 88040-900 Florianópolis - SC, Brasil
}

Recebido em 4/11/05; aceito em 23/6/06; publicado na web em 28/11/06

\begin{abstract}
INFLUENCE OF THE EXTRACTION METHODOLOGY ON THE METHYLXANTHINES CONTENT OF MATÉ (Ilex paraguariensis A. ST.-HIL., AQUIFOLIACEAE). Ilex paraguariensis A. St. -Hil. is a native species of southern South America. The caffeine content in Ilex paraguariensis leaves has been considered an important quality parameter for maté-derived products. In this work different extraction methods for the determination of these methylxantines are compared. The influence of the extraction conditions on the methylxanthine yields was evaluated. Extraction by decoction with acidic aqueous solution $\left(\mathrm{H}_{2} \mathrm{SO}_{4} 4 \mathrm{~N}\right)$ presented the higher efficiency in the theobromine extraction. The extraction in a Soxhlet with acidic aqueous solution and decoction with acidic aqueous solution showed the highest caffeine yield. For the concomitant theobromine and caffeine quantification, the decoction with acidic aqueous solution is suggested.
\end{abstract}

Keywords: mate; Ilex paraguariensis; methylxanthines.

\section{INTRODUÇÃO}

Ilex paraguariensis A. St. -Hil. é uma espécie nativa das regiões subtropicais e temperadas da América do Sul, onde é popularmente conhecida como erva-mate. Utilizada no preparo do chimarrão, faz parte dos hábitos culturais da Argentina, do Uruguai, Paraguai e Brasil. Neste contexto, a erva-mate assume um papel sócioeconômico importante, na medida em que é, basicamente, produzida em pequenas propriedades rurais, alcançando uma produção anual de $500.000 \mathrm{t}^{1}$.

A propriedade estimulante da erva-mate, relacionada com a presença de metilxantinas, é conhecida e explorada há séculos ${ }^{2}$. A cafeína 1 foi isolada de folhas de Ilex paraguariensis em 1843 por Stenhouse $^{2}$. Já Oehrli ${ }^{3}$ relatou, pela primeira vez, em 1927, a presença de teobromina 2. A presença de teofilina 3 na erva-mate é controversa. Mazzafera ${ }^{4}$ observou a ocorrência desta substância em pequenas quantidades, enquanto que outros pesquisadores não detectaram sua presença ${ }^{5-8}$.<smiles>Cn1c(=O)c2c(ncn2C)n(C)c1=O</smiles>

1

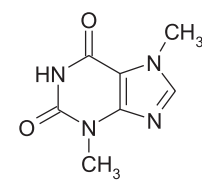

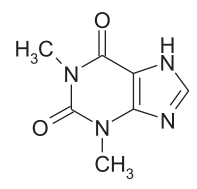

3
Figura 1. Estrutura química das metilxantinas; 1: cafeína, 2: teobromina, 3: teofilina

De acordo com a literatura, o teor de metilxantinas na ervamate é extremamente variável, sendo apontado teores de cafeína desde 0,16 até $1,4 \%{ }^{7}$. A legislação em Vigilância Sanitária estabeleceu, em determinado momento (Brasil, 1998) ${ }^{9}$, a exigência de um teor mínimo de cafeína de $0,5 \%$, exigência essa revogada em

*e-mail: schenkel@ccs.ufsc.br
2002, quando foi estabelecido apenas um valor máximo para os produtos declarados como descafeinados (Brasil, 2002) ${ }^{10}$. A controversia em relação à exigência quanto ao teor mínimo de cafeína pode estar relacionada com a variabilidade das populações e plantas de Ilex paraguariensis, mas também ao método de extração aplicado na sua determinação. Até o presente, nenhum estudo comparativo sistemático entre os métodos foi relatado. Neste contexto, no presente trabalho foi delineado um estudo comparativo da eficiência de extração de cafeína e teobromina em sete métodos extrativos. Foi avaliada a influência de alguns parâmetros, dentre eles: o pré-tratamento com base, o tipo de solvente e a temperatura sobre a extração das metilxantinas.

\section{PARTE EXPERIMENTAL}

\section{Material vegetal}

Partes aéreas de Ilex paraguariensis foram coletadas em Mato Leitão, RS, Brasil. Uma exsicata da planta foi depositada no Herbário do Instituto de Botânica da Universidade Federal do Rio Grande do Sul sob o número ICN-(7787), Porto Alegre, Brasil. As partes aéreas foram processadas de acordo com o processamento tradicional, abrangendo o sapeco (processo que consiste no ato de submeter folhas e ramos da erva-mate recém-podada à ação das chamas de forma direta ou indireta, a fim de eliminar o excesso de umidade ${ }^{9}$ ), a secagem e a moagem, processamento esse realizado na ervateira Fino Mate, em Mato Leitão/RS, originando a matéria-prima analisada pelos sete métodos descritos a seguir.

\section{Equipamentos e reagentes}

Para os processos de extração do material vegetal e análise em camada delgada foram utilizados solventes de grau analítico (Merck). A análise cromatográfica em camada delgada foi realizada em pla- 
cas de gel de sílica (placas aluminizadas Merck, $60 \mathrm{~F}_{254}$ ), como eluente foi utilizada a mistura de solventes $\mathrm{CH}_{2} \mathrm{Cl}_{2}: \mathrm{EtOH}(90: 5$, v/ v), em câmara saturada. A detecção foi realizada através da observação da extinção de fluorescência sob luz $\mathrm{UV}_{254}$. A análise por cromatografia líquida de alta eficiência (CLAE) foi realizada em cromatógrafo líquido de alta eficiência Waters 600E, equipado com válvula de injeção Rheodyne ${ }^{\circledR}$ de volume fixo $(20 \mu \mathrm{L})$, detector UV Waters 486 de comprimento de onda variável e com integrador Waters 747 (Milford, USA). Foram utilizadas pré-coluna RP-18 (30$40 \mu \mathrm{m})$ e coluna Shim-Pack CLC-ODS (M) RP-18 (5 $\mu \mathrm{m}, 250$ x 4 $\mathrm{mm}$ d.i.). Os solventes usados foram metanol para HPLC (Lichrosolv, Merck, USA) e água purificada por meio do sistema Milli-Q (Millipore Corp., Bedford, USA). Cafeína, teobromina e teofilina, grau analítico, de procedência Sigma/Aldrich (St. Louis, USA), foram utilizadas como substâncias de referência.

\section{PROCESSOS DE EXTRAÇÃO}

Método I: Método de Baltassat et al. ${ }^{12}$, modificado. A uma amostra de $2 \mathrm{~g}$ da matéria-prima foram adicionados $20 \mathrm{~g}$ de areia purificada. Essa mistura foi colocada em maceração por $2 \mathrm{~h}$ com $10 \mathrm{~mL}$ de uma solução aquosa $25 \%$ (v/v) de $\mathrm{NH}_{4} \mathrm{OH}$. A mistura foi submetida à extração em um extrator tipo Soxhlet, com $200 \mathrm{~mL}$ de uma mistura clorofórmio:isopropanol $(3: 1, \mathrm{v} / \mathrm{v})$, durante $4 \mathrm{~h}$.

Método II: similar ao método I, exceto quanto à alcalinização, que foi excluída.

Método III: A uma amostra de $2 \mathrm{~g}$ da matéria-prima foram adicionados $20 \mathrm{~g}$ de areia purificada. Essa mistura foi colocada em maceração por $2 \mathrm{~h}$ com $10 \mathrm{~mL}$ de uma solução aquosa $25 \%(\mathrm{v} / \mathrm{v})$ de $\mathrm{NH}_{4} \mathrm{OH}$. A mistura foi submetida à extração em um extrator tipo Soxhlet, com $200 \mathrm{~mL}$ de água, durante $4 \mathrm{~h}$.

Método IV: similar ao método III, excluindo-se a fase de alcalinização.

Método V: Uma amostra de $2 \mathrm{~g}$ da matéria-prima, adicionada de $20 \mathrm{~g}$ de areia purificada, foi colocada em um extrator tipo Soxhlet e submetida à extração com 200 mL de $\mathrm{H}_{2} \mathrm{SO}_{4} 4 \mathrm{~N}$ (aquoso) durante $4 \mathrm{~h}$. O extrato resultante foi filtrado e neutralizado com uma solução de $\mathrm{NH}_{4} \mathrm{OH} 25 \%$ (v/v) e submetido à extração, subseqüentemente, com quatro porções de $50 \mathrm{~mL}$ de uma mistura de clorofórmio: isopropanol $(3: 1, v / v)$ que foram reunidas.

Método VI: Segundo Reginatto et al. ${ }^{7}$, uma amostra de $2 \mathrm{~g}$ da matéria-prima foi mantida em ebulição, durante 10 min com 150 $\mathrm{mL} \mathrm{de} \mathrm{H}_{2} \mathrm{SO}_{4} 4 \mathrm{~N}$ (aquoso). $\mathrm{O}$ extrato foi filtrado e o filtrado tratado como no método $\mathrm{V}$.

Método VII: Uma amostra de $2 \mathrm{~g}$ da matéria-prima foi mantida em ebulição, durante $10 \mathrm{~min}$, com $150 \mathrm{~mL}$ de água. O extrato resultante foi filtrado e submetido à extração, subseqüentemente, com quatro porções de $50 \mathrm{~mL}$ de uma mistura de clorofórmio:isopropanol $(3: 1, \mathrm{v} / \mathrm{v})$ que foram reunidas.

As diferenças entre as metodologias utilizadas estão descritas na Tabela 1.

\section{Avaliação do teor de metilxantinas}

\section{Condições cromatográficas}

A fase móvel foi constituída por uma mistura de metanol:água (4:6, v/v) em fluxo de $1,1 \mathrm{~mL} / \mathrm{min}$. A detecção foi realizada em $280 \mathrm{~nm}$.
Tabela 1. Diferenças entre os métodos utilizados para a extração de metilxantinas da erva-mate

\begin{tabular}{lcccc}
\hline Método & $\begin{array}{c}\text { Alcalinização } \\
\text { prévia }\end{array}$ & $\begin{array}{c}\text { Processo } \\
\text { extrativo }\end{array}$ & Acidificação & $\begin{array}{c}\text { Solvente } \\
\text { extração final }\end{array}$ \\
\hline I & SIM & Soxhlet & NÃO & $\begin{array}{c}\text { Clorofórmio: } \\
\text { isopropanol } \\
\text { Clorofórmio: } \\
\text { II }\end{array}$ \\
NÃO & Soxhlet & NÃO & Áopanol \\
III & SIM & Soxhlet & NÃO & Água \\
IV & NÃO & Soxhlet & NÃO & Água \\
V & NÃO & Soxhlet & SIM & Água* \\
VI & NÃO & Decocção & SIM & Água* \\
VII & NÃO & Decocção & NÃO & Água* \\
\hline
\end{tabular}

*após essa extração inicial, as metilxantinas foram extraídas da fase aquosa com a mistura clorofórmio:isopropanol(3:1,v/v)

\section{Curva padrão}

Curvas padrão de cafeína e teobromina (proveniência Sigma, grau p.a.) foram obtidas por meio da análise de soluções metanólicas destes padrões nas concentrações de 0,$34 ; 0,85 ; 3,39 ; 5,01 ; 8,48 ; 16,96$ e $42,40 \mu \mathrm{g} / \mathrm{mL}$ para cafeína e 0,$32 ; 0,81 ; 1,62 ; 3,23$ e $4,85 \mu \mathrm{g} / \mathrm{mL}$ para teobromina. Todas as soluções padrões foram previamente filtradas em membrana hidrofílica GV (Durapore ${ }^{\circledR}$ ) com diâmetro nominal de poro de $0,45 \mu \mathrm{m}$ e injetadas no cromatógrafo, em triplicata. As áreas dos picos foram medidas, sendo determinados a média, o desvio-padrão e o desvio-padrão relativo para cada um dos pontos. As médias dos valores das áreas referentes a cada concentração foram plotadas em gráfico de concentração versus área, calculando-se o coeficiente de regressão linear da curva e a equação da reta.

Limites de detecção e quantificação

Os limites de detecção (LD) e de quantificação (LQ) da cafeína e da teobromina foram determinados de acordo com o estabelecido pela $\mathrm{ICH}^{11}$, baseando-se no desvio-padrão (DP) do intercepto do coeficiente angular (S) da curva de calibração, por meio das Equações 1 e 2.

$$
\begin{aligned}
& L D=D P \times 3,3 / S \\
& L Q=D P \times 10 / S
\end{aligned}
$$

\section{Amostras}

As soluções extrativas obtidas em cada método foram filtradas e diluídas até a concentração necessária para a análise por CLAE, dentro da faixa de linearidade avaliada para o método (cafeína: 0,34-42,4 $\mu \mathrm{g}$ / $\mathrm{mL}$; teobromina: $0,32-4,85 \mu \mathrm{g} / \mathrm{mL}$ ). As áreas dos picos correspondentes à cafeína e teobromina foram medidas e as concentrações calculadas por meio das correspondentes curvas padrão. Cada método extrativo foi repetido três vezes. De cada uma destas soluções extrativas foram retiradas três amostras, totalizando nove amostras por método extrativo, que foram analisadas em triplicata por CLAE.

\section{RESULTADOS E DISCUSSÃO}

$\mathrm{Na}$ análise qualitativa para metilxantinas foi detectada a presença da cafeína e da teobromina, mas não da teofilina, o que está de acordo com resultados anteriores obtidos em nosso grupo de trabalho e já relatados ${ }^{7,15}$. Para as análises qualitativa e quantitativa foi utilizada a CLAE, com metodologia já validada para análise de metilxantinas em extratos de Ilex paraguariensis ${ }^{7,8}$. No sistema 
cromatográfico empregado, os padrões teobromina e cafeína apresentaram, respectivamente os tempos de retenção de 4,8 e 9,4 min. A Figura 2 apresenta exemplos dos cromatogramas das substâncias de referência e das soluções extrativas.

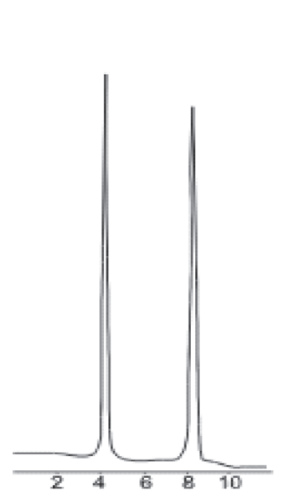

(a)

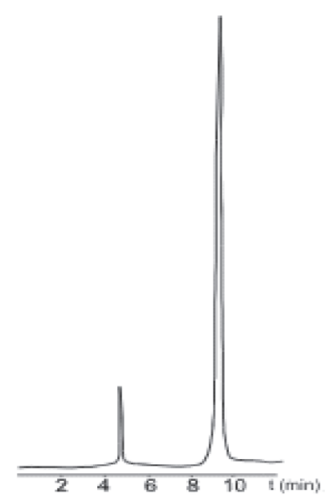

(b)
Figura 2. (a) Perfil cromatográfico dos padrões de teobromina ( $\mathrm{tr}=4,8 \mathrm{~min}$ ) e cafeína (tr = 9,4 min); (b) perfil cromatográfico de metilxantinas presentes em Ilex paraguariensis, extração pelo Método I

As curvas de calibração da cafeína e teobromina mostraram-se lineares nas faixas de concentração empregadas, apresentando, respectivamente, coeficientes de regressão $\left(r^{2}\right) 0,9987$ e 0,9996 . A equação da reta obtida por regressão linear para cafeína foi $\mathrm{y}_{\mathrm{c}}=115984 \mathrm{x}_{\mathrm{c}}$ +58362 , e para teobromina, $\mathrm{y}_{\mathrm{t}}=121341 \mathrm{x}+2788,2$, onde $y$ representa a área do pico (mV.s) e $x$ representa a concentração de cafeína ou de teobromina $(\mu \mathrm{g} / \mathrm{mL})$.

O limite de detecção da cafeína foi de $0,03 \mu \mathrm{g} / \mathrm{mL}$ e o da teobromina, de $0,09 \mu \mathrm{g} / \mathrm{mL}$. No que se refere aos limites de quantificação, a cafeína apresentou o limite de $0,09 \mu \mathrm{g} / \mathrm{mL}$ e a teobromina, de $0,30 \mu \mathrm{g} / \mathrm{mL}$.

As concentrações de cafeína e teobromina obtidas em cada método são apresentadas na Tabela 2, assim como a relação entre os teores de cafeína e teobromina, para cada método. Os valores apresentados são resultado da aplicação de ANOVA e Tukey.

Tabela 2. Conteúdo de metilxantinas ( $\%$, teores médios, $n=3$ ) em Ilex paraguariensis obtido por diferentes métodos e relação cafeína/ teobromina $(\mathrm{C} / \mathrm{T})$

\begin{tabular}{lccr}
\hline & Cafeína $(\%)^{*}$ & Teobromina $(\%)^{*}$ & $\mathrm{C} / \mathrm{T}$ \\
\hline Método I & $0,69^{\mathrm{b}}$ & $0,07^{\mathrm{c}}$ & 9.8 \\
Método II & $0,22^{\mathrm{c}}$ & $0,02^{\mathrm{d}}$ & 11.5 \\
Método III & $0,25^{\mathrm{c}}$ & $0,02^{\mathrm{d}}$ & 12.5 \\
Método IV & $0,14^{\mathrm{d}}$ & $0,01^{\mathrm{e}}$ & 14.0 \\
Método V & $0,79^{\mathrm{a}}$ & $0,16^{\mathrm{b}}$ & 4.9 \\
Método VI & $0,71^{\mathrm{b}}$ & $0,51^{\mathrm{a}}$ & 1.4 \\
Método VII & $0,67^{\mathrm{b}}$ & $0,07^{\mathrm{c}}$ & 9.5 \\
\hline
\end{tabular}

* g de metilxantinas em $100 \mathrm{~g}$ de material vegetal $(\%, \mathrm{~m} / \mathrm{m}) . \mathrm{C} / \mathrm{T}=$ relação entre teores de cafeína e teobromina. ${ }^{\mathrm{a}, \mathrm{b}, \mathrm{c}, \mathrm{d}, \mathrm{e}}$ letras diferentes, entre métodos, indicam diferença estatística com base em ANOVA e teste de Tukey $(\mathrm{p}<0,05)$.

\section{Influência dos métodos de extração sobre os teores de cafeína}

Comparando-se os métodos de extração I a IV, que têm em comum a forma de extração (Soxhlet) e se diferenciam quanto à alcalinização prévia e o líquido extrator, o método I (alcalinização; extração com clorofórmio:isopropanol) mostrou-se o mais eficiente. A explicação para este fato está provavelmente relacionada com a ocorrência das metilxantinas nos vegetais sob a forma de complexos ${ }^{13,14}$. Os diferentes teores obtidos nos métodos I e II indicam que a alcalinização libera as metilxantinas de seus complexos, deixando-as na forma livre, de maior solubilidade. A comparação entre os métodos I e III denota a maior solubilidade da forma livre, de características básicas, na mistura clorofórmio:isopropanol (3:1) em relação à água.

A acidificação utilizada nos métodos V (extração em Soxhlet) e VI (extração por decocção) conduziu aos maiores rendimentos, o que está provavelmente relacionado com a descomplexação e com a protonação das metilxantinas, o que as torna muito mais solúveis em água. Comparando esses dois últimos resultados, o método $\mathrm{V}$ levou a rendimentos maiores que o método VI, o que está associado, provavelmente, ao maior tempo de extração empregado no método $\mathrm{V}(4 \mathrm{~h})$, bem como à continua renovação do solvente, já que essa extração foi realizada em Soxhlet.

A comparação entre os métodos IV (extração em Soxhlet; água) e VII (extração por decocção; água) indica a superioridade da decocção em relação à extração por Soxhlet, quando não há a ação do ácido sulfúrico. Esse aumento do rendimento pode estar relacionado com o efeito da temperatura sobre a complexação, mas também com o aumento da solubilidade da cafeína com o aumento da temperatura na decocção.

\section{Influência dos métodos de extração sobre os teores de teobromina}

A teobromina é uma substância de baixa solubilidade, tanto em clorofórmio quanto em água. Nos experimentos realizados utilizando-se extração em Soxhlet, foi observado um aumento no rendimento quando o solvente escolhido foi clorofórmio:isopropanol com prévia alcalinização da amostra (método I). Esses resultados indicam que a alcalinização, da mesma forma que para cafeína, libera a teobromina da forma conjugada na planta, deixando-a livre para extração com o solvente empregado, contudo, sua reduzida solubilidade determina rendimentos baixos, principalmente quando o solvente é água (método III).

Os rendimentos obtidos pelos métodos V (extração em Soxhlet) e VI (extração por decocção), ambos em meio ácido comprovam a importância da acidificação para a extração da teobromina, da mesma forma que para a cafeína, o que está provavelmente relacionado com a descomplexação e com a protonação das metilxantinas e conseqüente aumento da solubilidade em água. Cabe destacar a diferença de rendimento entre esses dois métodos, o que indica a maior eficiência da decocção para a extração da teobromina, que pode ser explicado pela influência da alta temperatura (próxima a $100{ }^{\circ} \mathrm{C}$ ) sobre a solubilidade dessa metilxantina.

As diferenças de teores com os diferentes métodos são claramente visualizadas pela observação da relação cafeína:teobromina, que passa de 14 no método IV para 1,4 no método VI, sendo este último o que apresenta a maior eficiência na extração da teobromina.

\section{CONCLUSÃO}

Pode-se concluir que a eficiência na extração de metilxantinas depende da sua solubilidade nos solventes empregados. A água quente mostrou ser o melhor solvente para o material vegetal sem tratamento prévio (método VII). A extração por decocção mostrou-se mais eficiente que a extração por Soxhlet. O melhor resultado foi obtido com a acidificação e por decocção (método VI), por conjugar bons rendimentos para ambas as metilxantinas. A utilização de solução ácida leva, provavelmente, à protonação das moléculas de cafeína e teobromina, 
proporcionando um aumento na solubilidade em água de ambas as moléculas, a qual é incrementada pela elevação da temperatura.

Em suma, o presente trabalho demonstra que a metodologia de extração influencia diretamente o teor de metilxantinas em erva-mate. Os baixos teores de teobromina referidos em alguns trabalhos podem ser decorrentes das condições utilizadas no processo de extração, geralmente adequadas para cafeína, mas não para teobromina, como no caso da extração com clorofórmio. É importante ressaltar que o alto teor de teobromina verificado em erva-mate está de acordo com outros resultados obtidos em nosso grupo de trabalho ${ }^{7,15}$. Isso indica que a erva-mate não é uma planta que apresenta apenas teores elevados de cafeína, como refere a literatura de modo geral, mas também é uma planta que possui elevados teores de teobromina.

\section{REFERÊNCIAS}

1. IBGE - Instituto Brasileiro de Geografia e Estatística. Censo agropecuário 2001, http://www.sidra.ibge.gov.br, acessada em Outubro 2005.
2. Peckolt, G.; Rev. Flora Medicina 1943, 10, 493.

3. Oehrli, A.; Pharm. Acta Helv. 1927, 2, 155.

4. Mazzafera, P.; Rev. Bras. Fisiol. Veg. 1994, 6, 149.

5. Clifford, M.N.; Martinez, J. R.; Food Chem. 1990, 35, 13.

6. Filip, R.; Lopez, P.; Coussio, J.; Ferraro, G.; Phytotherapy Res. 1998, 12, 129.

7. Reginatto, F. H.; Athayde, M. L.; Gosmann, G.; Schenkel, E. P.; J. Braz. Chem. Soc. 1999, 10, 443

8. Athayde, M. L.; Coelho, G. C.; Schenkel, E. P.; Phytochemistry 2000, 55, 853.

9. BRASIL. Ministério da Saúde. Secretaria de Vigilância Sanitária; portaria $n^{\circ} 234$, de 25 de março de 1998, Diário Oficial da União, 26/03/1998.

10. BRASIL. Agência Nacional De Vigilância Sanitária; Resolução RDC nº 302, Diário Oficial da União, 08/11/2002.

11. http://www.ich.org, acessada em Março 2005.

12. Baltassat, F.; Darbour, N.; Ferry, S.; Plantes Médic. Phytothérapie 1984, 18,195

13. Martin, R.; Lilley, T. H.; Falshaw, C. P.; Haslam, E.; Begley, M. J.; Magnolato, D.; Phytochemistry 1987, 26, 273.

14. Waldhauser, S. S. M.; Baummann, T. W.; Phytochemistry 1996, 42, 985.

15. Coelho, G. C.; Athayde, M. L.; Schenkel, E. P.; Braz. J. Pharm. Sci., 2001, 37, 154. 